\title{
Value of staging squamous cell carcinoma of the anal margin and canal using the sentinel lymph node procedure: an update of the series and a review of the literature
}

\author{
D M Mistrangelo*,1, M Bellò ${ }^{2}, \mathrm{P}^{*}$ Cassoni ${ }^{3}, \mathrm{E} \mathrm{Milanesi}^{4}, \mathrm{P}$ Racca ${ }^{4}, \mathrm{~F} \mathrm{Munoz}{ }^{5}, \mathrm{G} \mathrm{Fora}^{4}, \mathrm{~N}$ Rondi ${ }^{5}, \mathrm{~N}$ Gilbo ${ }^{1}$, \\ R Senetta ${ }^{3}, \mathrm{U}^{\text {Ricardi }}{ }^{5}$ and $M$ Morino $^{1}$ \\ ${ }^{1}$ Digestive and Colorectal Surgical Department, Centre of Minimal Invasive Surgery, University of Turin, Molinette Hospital, \\ Turin, Italy; ${ }^{2}$ Department of Nuclear Medicine, University of Turin, Molinette Hospital, Turin, Italy; ${ }^{3}$ Department of Biomedical \\ Sciences and Human Oncology, University of Turin, Molinette Hospital, Turin, Italy; ${ }^{4}$ Oncological Centre for Gastrointestinal \\ Neoplasms, Molinette Hospital, Turin, Italy and ${ }^{5}$ Department of Radiotherapy, University of Turin, Molinette Hospital, Turin, Italy
}

Background: Inguinal metastases in patients affected by anal cancer are an independent prognostic factor for local failure and overall mortality. Since 2001, sentinel lymph node biopsy was applied in these patients. This original study reports an update of personal and previous published series, which were compared with Literature to value the incidence of inguinal metastases T-stage related and the overall incidence of false negative inguinal metastases at sentinel node.

Methods: In all, 63 patients diagnosed with anal cancer submitted to inguinal sentinel node. Furthermore a research in the Pub Med database was performed to find papers regarding this technique.

Results: In our series, detection rate was 98.4\%. Inguinal metastases were evidentiated in 13 patients (20.6\%). Our median follow-up was 35 months. In our series, no false negative nodes were observed.

Conclusion: Sentinel node technique in the detection of inguinal metastases in patients affected by anal cancer should be considered as a standard of care. It is indicated for all T stages in order to select patients to be submitted to inguinal radiotherapy, avoiding related morbidity in negative ones. An overall $3.7 \%$ rate of false negative must be considered acceptable.

Anal cancer remains a rare disease. An estimated 5820 new cases (2140 men and 3680 women) were estimated to occur in the United States in 2011, accounting for approximately $2.1 \%$ of digestive system cancers. It has been estimated that 770 deaths due to anal cancer will occur in United States alone in 2011 (Siegel et al, 2011).

In recent years, fluorodeoxyglucose-positron emission tomography/computed tomography (18F-FDG-PET/CT) (Mistrangelo et al, 2012) and sentinel lymph node biopsy (SLNB) of inguinal nodes have been introduced in clinical practice.

SLNB was proposed in 2000 by John Spratt, who suggested that prophylactic groin dissection is not required, but it may be curative in many cases for enlarged nodes or in the presence of a positive SLNB (Spratt, 2000).

Since 2001, SLNB was applied in patients affected by anal cancer providing inguinal staging and permitting a better planning of 
radiotherapic planes, avoiding inguinal radiotherapy and related morbidity in patients without metastasis at SLNB (Keshtgar et al, 2001).

Up to now, several studies (Vajda et al, 2001; Mistrangelo et al, 2002; Peley et al, 2002; Rabbit et al, 2002; Bobin et al, 2003; Damin et al, 2003; Ulmer et al, 2003; Castro et al, 2005; Gretschel et al, 2008; Mariani et al, 2008; Mistrangelo et al, 2009a; Hirche et al, 2010; De Nardi et al, 2011) and two reviews (Damin et al, 2006; Mistrangelo et al, 2009b) were published in international Literature. All reports agree that SLNB for staging inguinal nodes in anal cancer is easy, feasible and can help to detect occult inguinal metastatic disease, in order to select the patients to submit to inguinal radiotherapy. Gretschel et al (2008) precised that SLNB is mainly indicated in T1 and T2 tumours and it is not recommendable for larger (T3-T4) tumours, considering the high incidence of inguinal metastases (MTS), and in patients with previous surgical manipulation in the anal or inguinal region.

Therefore, in 2010, De Jong et al (2010) reported a limited value of staging squamous cell carcinoma of the anal margin and canal using the sentinel node procedure in a prospective study with long-term follow up. The authors conclude that, because of the occurrence of inguinal lymph node MTS after a tumour-negative SLNB, the introduction of this procedure as a standard of care in all patients with anal carcinoma should be done with caution to avoid undertreatment of patients who otherwise would benefit from inguinal radiotherapy.

Considering these late reports, we revised our series and those reported in Literature to value the incidence of inguinal MTS T-stage related and the incidence of false negative (FN) SLNB in order to confirm or exclude indication to SLNB in all T stages for patients affected by anal cancer.

\section{PATIENTS AND METHODS}

The study population consisted of 63 patients with anal cancer submitted to SLNB. The study was approved by the local ethics committee. The presenting symptoms were bleeding on defecation, sometimes associated with anal pain or the sensation of an anal mass.

Clinical workup comprised digital rectal examination, anoscopy, rigid proctoscopy, clinical exam of inguinal nodes, total colonoscopy, CT scan, rectal endosonography and PET-CT scan. HIV status and related CD4 count were valued in order to verify if there is a correlation with inguinal MTS. Patients with perianal cancer were excluded from the study.

All patients except those with an important palpable inguinal lymphadenopathy were studied for inguinal MTS with SLNB technique.

All patients were informed about the procedure and gave their written informed consent.

The technique of SLNB was previously decribed (Mistrangelo et al, 2009a).

The procedure started with the radioisotope injection. We performed it in a time ranging between 3 and $24 \mathrm{~h}$ before surgery. The injection of the radiopharmaceutical should be carried out in the Nuclear Medicine Department in order to adhere to universal radiation-safety precautions. We used Nanocoll, which is characterised by particles with a diameter of $80 \mathrm{~nm}$, which are perfect for an adequate migration.

All patients studied in our Department were injected with $37 \mathrm{MBq}$ of nanocoll-Tc-99 $\mathrm{m}$ dextran 500 in a total volume of $0.4 \mathrm{ml}$, divided in four insulin syringes with a total volume of $0.1 \mathrm{ml}$ per syringe. The injection was performed at the four cardinal points around the neoplasm.
The injection could be performed directly in the case of a neoplasm located perianally or at the anal margin, while in case of neoplasms located in the anal canal, we used a disposable anoscope to achieve a correct injection of the nanocolloid around the neoplasm. For the administration of the substance, we used a 22-G needle.

The procedure did not require anaesthesia and it did not present complications. A little pain in the injection site lasting few minutes was usually reported by the patient.

Planar lymphoscintigraphic images were generally performed $2-3 \mathrm{~h}$ after injection. Images were obtained using a GE Millennium gamma camera (GE Healthcare, Milwaukee, WI, USA). It presents a high-resolution collimator and a rectangular detector with 59 photomultipliers and crystal thickness of 5/8 inch. Acquistion window was set at $140 \mathrm{KeV}( \pm 10 \%)$. The matrix of planar images was $256 \times 256$. The images were obtained in an anterior and posterior view. Sometimes we performed a lateral scintigraphic view as well.

Lymphoscintigraphy obtained with colloid particles permits easy evaluation of the main lymphatic drainage, showing the first node in which the tracer is captured. Colloids have the advantage of delayed wash out allowing the surgical procedure the same day or the day following the injection.

Imaging analysis was performed by two readers, who participated in all phases of the procedure.

The same day of the injection or the following day patients were submitted to inguinal SLNB in the operating theatre. No difference in terms of signal detection or accuracy was noted between the two groups. The procedure started with the localisation of the sentinel node. It was carried out with the use of a manual portable gamma probe. We used a Scintiprobe MR 100, Politech, Carsoli, Italy. To read the signal, the probe was directed away from the anus in order to remove the signal originating from the site of injection. When the positive signal was found, a cutaneous mark was positioned in order to fix the point of surgical incision. Generally, the surgical procedure was done under local anaesthesia. Under signal guidance, the biopsy of sentinel lymph node/s was performed. We considered a signal to be positive only when node and background radioactivity signal ratio was equal or superior to $5: 1$. We measured the radioactivity of the resected node to confirm its positivity after removal. Then we evaluated the persistence of radioactivity in the inguinal area in order to locate further sentinel nodes. We performed the procedure bilaterally in case of lymphoscintigraphy or intraoperative signal positive for bilateral migration. Nodes were then submitted to microscopic evaluation: 5-10 microsections at representative levels of each sentinel lymph node were obtained by a step sectioning technique for nodes $>5 \mathrm{~mm}$. These sections were stained with hematoxylin and eosin. If the SLN was classified free of MTS after routine hematoxylin and eosin examination, immunohistochemistry was performed by means of an anti-pancytokeratin antibody (AE1/AE3) in order to identify micrometastases or isolated tumour cells.

Then patients were stratified for $\mathrm{T}$ stage in order to determine the incidence of inguinal MTS for each stage.

On completion of pre-treatment assessment, patients were submitted to combined radiochemotherapy (RCT) treatment (Mistrangelo et al, 2009a; Mistrangelo et al, 2010; Mistrangelo et al, 2012). Inguinal radiotherapy was administered only to patients with metastatic inguinal lyph nodes at SLNB.

At 1 and 3 months after the completion of RCT, patients underwent rectal digital examination, anoscopy with biopsy and PET/CT. Then patients were submitted to a follow-up consisting of a digital rectal examination, anoscopy, clinical exam of inguinal nodes and tumour marker assay (CEA and CA 19-9, that are not specific, and only recently sieric YKL-40) every 3 months for 3 years and every 6 months in the following 2 years. A CT scan of the thorax and abdomen was performed yearly for 5 years. 
After the first 5 years, patients were submitted to a rectal examination, anoscopy, clinical exam of inguinal nodes and tumour marker assay every year for further 5 years. A CT scan was performed 8 and 10 years after the end of RCT.

This accurate follow-up was performed to state the results of RCT, the incidence of persistence/recurrence of the disease and the incidence of inguinal MTS.

Moreover, the follow-up was oriented to value the incidence of FN in SLNB (patients with an histological negative SLNB, but developing inguinal MTS within the first 6 months of follow up). and to compare our results with ones published in Literature after a bibliographic research on Pub Med database. All papers, including case reports, are evaluated.

Statistical analysis. Data are presented as means ( \pm s.d.) or median and range and rate with percentage for continuous and categorical variables, respectively.

\section{RESULTS}

Between November 2001 and May 2011, 63 patients with anal cancer were studied at our Department. Tumour biopsy revealed 63 squamous cell carcinomas. Patient characteristics are reported in Table 1.

Migration of Nanocoll was bilateral in 37 patients (59.7\%) and unilateral in 25 patients $(40.3 \%)$.

Detection rate was $98.4 \%$ (62 out of 63 patients). Median number of excised lymph nodes was 4 (range 1-14).

Histological exam evidentiated inguinal MTS in 13 patients (20.6\%). In all, 2 (15.4\% of inguinal metastatic patients) of these patients presented bilateral inguinal MTS. In 1 (7.7\%) of metastatic cases, micrometastases were found. No cases of isolated tumour cells were evidentiated in our series.

Regarding HIV + status, only 1 patient presented MTS $(6.7 \%$ of $\mathrm{HIV}+$ patients). This patient had a CD $4+$ count $=163$. Considering this aspect, only three patients had a CD $4+$ count $<200$ (20\%).

Incidence of inguinal MTS in HIV - patients was 25\% (12 out of 48).

Patients with inguinal metastatic disease were stratified for $\mathrm{T}$ stage (Table 2).

In 53 patients, PET-CT was performed and compared with SLNB in 41 patients (Mistrangelo et al, 2012). PET/CT was

\begin{tabular}{|l|c|}
\hline \multicolumn{2}{|l|}{ Table 1. Patient characteristics } \\
\hline Patient Characteristics & No. of patients (\%) \\
\hline Sex & 63 \\
Male & $24(38.1)$ \\
Female & $39(61.9)$ \\
\hline Race & \\
White & $63(100)$ \\
\hline Age (years) & \\
Median & 59 \\
Range & $32-82$ \\
HIV-seropositive & $15(23.8)$ \\
\hline Localisation & \\
Anal canal & $43(68.2)$ \\
Anal margin & $20(31.7)$ \\
\hline T & $7(11.1)$ \\
T1 & $35(55.5)$ \\
T2 & $17(26.9)$ \\
T3 & $4(6.3)$ \\
\hline
\end{tabular}

positive for inguinal MTS in 12 of 53 patients (22.6\%) and negative in 41 of 53 patients $(77.4 \%)$. Inguinal node staging was compared with the results of SLNB, which was performed in 41 patients. Comparison between SLNB and PET/CT findings showed that SLNB confirmed the presence of inguinal MTS in only 8 cases, with 4 of 41 patients $(9.7 \%)$ false positive and 2 of 41 patients (4.9\%) FN.

Median follow-up was 35 months (range 3-86 months). In the first 6 months of follow up, none FN inguinal MTS occurred in our series. During follow-up, none of the patients negative for inguinal MTS at SLNB deveoped metachronous MTS.

\section{DISCUSSION}

Anal cancer remains a rare disease but its incidence is increasing (Siegel et al, 2011), mainly in association with human papillomaviruses infection.

Since 1974, multimodality treatment as proposed by Nigro et al (1974), which combines radiation and chemotherapy, has become the standard of care, with surgery reserved for salvage treatment following local failure.

The overall 5-year survival rate reaches $70 \%$ in the absence of inguinal MTS (Gerard et al, 2001), which are an independent prognostic factor for local failure and overall mortality according to a multivariate analysis in a phase 3 EORTC trial (Bartelink et al, 1997). The average incidence rate of synchronous inguinal MTS is $13 \%$ (range 3-23\%), but if metachronous inguinal MTS are taken into account, the overall rate of inguinal involvement is $24 \%$ (16$36 \%)$ (Gerard et al, 2001). Inguinal involvement is usually unilateral, with $<5 \%$ bilateral either synchronous or metachronous extension (Gerard et al, 2001). Gerard et al (2001) reported a severe prognosis for patients with clinically large inguinal lymph nodes (37\% 5-year overall survival rate for patients with lymph nodes $>2 \mathrm{~cm}$ in greatest dimension), for patients with anal margin involvement (22.7\%), and for patients with T3-T4 lesions (39\%). Otherwise, the presence of concomitant perirectal lymph nodes did not significantly affect the prognosis.

Considering these aspects, the detection of inguinal lymph nodes is mandatory in the treatment of these patients and for their prognosis.

An array of tools for assessing inguinal metastasis have been proposed: clinical examination, endosonography, CT and magnetic resonance imaging; however, they are unable to detect nodal involvement in all the cases. Furthermore, only histological study can confirm MTS in a enlarged node or a micrometastasis in a normal-sized node. Wade et al (1989) at the Roswell Park Cancer Institute using a 'clearing technique' found that $44 \%$ of perianal, perirectal and pericolonic lymph node MTS were $<5 \mathrm{~mm}$ in diameter, and therefore indetectable by usual diagnostic tools.

Recently, the use of FDG PET has also gained an important place in this setting, even if its role has yet to be defined (Mistrangelo et al, 2010; Mistrangelo et al, 2012). To better diagnose inguinal MTS, in recent years, SLNB has proven to be a safe and an effective technique (Spratt, 2000; Keshtgar et al, 2001; Vajda et al, 2001; Mistrangelo et al, 2002; Peley et al, 2002; Rabbit et al, 2002; Bobin et al, 2003; Damin et al, 2003; Ulmer et al, 2003; Castro et al, 2005; Damin et al, 2006; Gretschel et al, 2008; Mariani et al, 2008; Mistrangelo et al, 2009a; De Jong et al, 2010; Hirche et al, 2010; De Nardi et al, 2011).

The present study confirms that SLNB is a simple and feasible technique with a high detection rate $(98.4 \%)$, as reported in Literature (47-100\%). Inguinal MTS are found in 20.6\% of cases (13 patients), comparable with Literature (range $9.1-33 \%$ in major published series). 
Table 2. Inguinal metastases stratified for T stage. Our experience and review of the Literature

\begin{tabular}{|c|c|c|c|c|c|c|}
\hline Author (year) & Patients & MTS & T1 & T2 & T3 & T4 \\
\hline Vajda et al (2001) & 2 & 0 & n.v. & n.v. & n.v. & n.v. \\
\hline Peley et al (2002) & 8 & 2 & n.v. & n.v. & n.v. & n.v. \\
\hline Perera et al (2003) & 12 & 2 & $0 / 2(0 \%)$ & $2 / 10(20 \%)$ & $0 / 0$ & $0 / 0$ \\
\hline Bobin et al (2003) & 33 & 7 & $0 / 3(0 \%)$ & $3 / 19$ (15.8\%) & $4 / 8(50 \%)$ & $0 / 2(0 \%)$ \\
\hline Damin et al (2006) & 22 & 2 & n.v. & n.v. & n.v. & n.v. \\
\hline Gretschel et al (2008) & 40 & $6 / 20$ & $4 / 7(57 \%)$ & $0 / 10(0 \%)$ & $2 / 3(66.6 \%)$ & $0 / 0(0 \%)$ \\
\hline Mariani et al (2008) & 25 & 0 & n.v. & n.v. & n.v. & n.v. \\
\hline De Nardi et al (2011) & 11 & 3 & $0 / 2(0 \%)$ & $1 / 4(25 \%)$ & $2 / 5(40 \%)$ & $0 / 0(0 \%)$ \\
\hline Hirche et al (2010) & 12 & 2 & $1 / 4(25 \%)$ & $0 / 5(0 \%)$ & $0 / 2(0 \%)$ & $1 / 1(100 \%)$ \\
\hline De Jong et al (2010) & 21 & 7 & $0 / 2(0 \%)$ & $6 / 15(40 \%)$ & $1 / 4(25 \%)$ & $0 / 0(0 \%)$ \\
\hline Francois et al (2010) & 34 & 5 & n.v. & n.v. & n.v. & n.v. \\
\hline Mistrangelo et al (this paper) & 63 & 13 & $1 / 7(14.3 \%)$ & $5 / 35$ (14.3\%) & $6 / 17$ (35.3\%) & $1 / 4(25 \%)$ \\
\hline Total valuables & 192 & $45 / 172(26.2 \%)$ & $6 / 27$ (22.2\%) & 17/98 (17.3\%) & 15/39 (38.5\%) & $2 / 7$ (28.6\%) \\
\hline
\end{tabular}

Table 3. Review of the Literature of SLNB with the count of false negative (FN)

\begin{tabular}{|c|c|c|c|c|c|c|c|c|}
\hline Author (year) & Patients & Localisation & $\begin{array}{l}\text { Palpable } \\
\text { nodes }\end{array}$ & $\begin{array}{l}\text { Detection } \\
\text { rate }\end{array}$ & Technique & MTS & $\mathrm{FU}(\mathrm{mo})$ & $\mathrm{FN}$ \\
\hline $\begin{array}{l}\text { Vajda et al } \\
\text { (2001) }\end{array}$ & 2 & Not specified & Not specified & $100 \%$ & Combined & $0 \%$ & $\begin{array}{c}\text { Not } \\
\text { specified }\end{array}$ & Not specified \\
\hline $\begin{array}{l}\text { Keshtgar et al } \\
(2001)\end{array}$ & 1 & Anal margin & No & $100 \%$ & Combined & $0 \%$ & $\begin{array}{c}\text { Not } \\
\text { specified }\end{array}$ & Not specified \\
\hline Peley et al (2002) & 8 & Not specified & Not specified & $100 \%$ & Combined & $25 \%$ & $5-35$ & $0 / 60 \%$ \\
\hline $\begin{array}{l}\text { Perera et al } \\
(2003)\end{array}$ & 12 & $\begin{array}{l}\text { Anal canal or } \\
\text { margin }\end{array}$ & Not specified & $67 \%$ & Combined & $29 \%$ & $\begin{array}{c}\text { Not } \\
\text { specified }\end{array}$ & Not specified \\
\hline $\begin{array}{l}\text { Bobin et al } \\
\text { (2003) }\end{array}$ & 33 & Not specified & No & $100 \%$ & Combined & $21 \%$ & 18 & $0 / 260 \%$ \\
\hline $\begin{array}{l}\text { Castro et al } \\
\text { (2005) }\end{array}$ & 2 & $\begin{array}{l}\text { Anal canal or } \\
\text { margin }\end{array}$ & No & $100 \%$ & Combined & $0 \%$ & $\begin{array}{c}\text { Not } \\
\text { specified }\end{array}$ & Not specified \\
\hline $\begin{array}{l}\text { Damin et al } \\
(2006)\end{array}$ & 22 & Not specified & No & $100 \%$ & Combined & $9.1 \%$ & $\begin{array}{c}\text { Not } \\
\text { specified }\end{array}$ & Not specified \\
\hline $\begin{array}{l}\text { Gretschel et al } \\
\text { (2008) }\end{array}$ & 40 & $\begin{array}{l}\text { Anal canal or } \\
\text { margin }\end{array}$ & Not specified & $\begin{array}{l}90 \% \text { (inguinal } \\
56 \% \text { ) }\end{array}$ & Nanocoll & $\begin{array}{c}30 \% \text { on } 20 \text { patients inguinal } \\
\text { SLNB }\end{array}$ & 27 & $1 / 147.1 \%$ \\
\hline $\begin{array}{l}\text { Mariani et al } \\
\text { (2008) }\end{array}$ & 25 & Not specified & Not specified & $100 \%$ & Combined & $0 \%$ & 20 & $2 / 258 \%$ \\
\hline $\begin{array}{l}\text { De Nardi et al } \\
\text { (2011) }\end{array}$ & 11 & Anal canal & No & $100 \%$ & Combined & $27.2 \%$ & 16 & $0 / 80 \%$ \\
\hline $\begin{array}{l}\text { Hirche et al } \\
\text { (2010) }\end{array}$ & 12 & $\begin{array}{l}\text { Anal canal or } \\
\text { margin }\end{array}$ & No & $83.3 \%$ & $\begin{array}{l}\text { Combined and } \\
\text { ICG }\end{array}$ & $20 \%$ & 44 & $0 / 80 \%$ \\
\hline $\begin{array}{l}\text { De Jong et al } \\
\text { (2010) }\end{array}$ & 21 & $\begin{array}{l}\text { Anal canal or } \\
\text { margin }\end{array}$ & No & $100 \%$ & Combined & $33 \%$ & 31 & $2 / 1414 \%$ \\
\hline $\begin{array}{l}\text { Francois et al } \\
\text { (2010) }\end{array}$ & 34 & $\begin{array}{l}\text { Anal canal or } \\
\text { margin }\end{array}$ & Not specified & $47 \%$ & Nanocis & $31.2 \%$ & 50 & $1 / 119 \%$ \\
\hline $\begin{array}{l}\text { Mistrangelo } \\
\text { et al (this paper) }\end{array}$ & 63 & $\begin{array}{l}\text { Anal canal or } \\
\text { margin }\end{array}$ & 14 & $98.4 \%$ & Nanocoll & $20.6 \%$ & 44.1 & $0 / 500 \%$ \\
\hline
\end{tabular}

In their paper, Gretschel et al (2008) concluded that the SLNB can be used to select patients for inguinal irradiation appropriately, especially in T1 and T2 tumours. These patients receive either additional treatment or are spared from unnecessary radiation. In their opinion, SLNB technique is not recommendable for larger T3-T4 tumours and in patients with previous surgical manipulation in the anal or inguinal region.

Published data up to date do not justify these conclusions. In fact, cumulative data evidentiated that almost 2 out of 3 of T3 and T4 patients are disease free from inguinal MTS at SLNB. Moreover, systematic irradiation of the groins has proved to demand a larger 
volume of radiotherapy, which increases toxicity especially when associated with chemotherapy: acute toxicity-related deaths occurred in 2-2.7\% of cases (Bartelink et al, 1997) and late toxicity related to primary treatment, such a small bowel injury, soft tissue injury and neurogenic bladder, was reported to be as high as $33 \%$, with $15 \%$ of patients requiring major medical or surgical intervention (Myerson et al, 2001). Otherwise in a study on 223 patients treated with chemoradiation sparing inguinal fields, Papillon and Montbarbon (1987) found metachronous inguinal MTS in only $7.4 \%$ of cases over a follow-up period of $>3$ years; and in a more recent study on 270 patients treated without elective inguinal irradiation, late inguinal MTS were diagnosed in $7.8 \%$ of patients (Gerard et al, 2001). In light of these results, authors concluded that the vast majority of patients (92\%) submitted to routine inguinal irradiation are actually being overtreated (Gerard et al, 2001). Following on these considerations, Sapienza et al (1992) suggested that the low incidence of metachronous MTS and the high morbidity after inguinal lymphadenectomy and radiotherapy do not advocate the choice of preventive treatment.

When we stratify patients for $\mathrm{T}$ stage, inguinal MTS are observed in $14.3 \%$ of $\mathrm{T} 1$ and $\mathrm{T} 2$ patients, $35.3 \%$ of $\mathrm{T} 3$ and $25 \%$ of $\mathrm{T} 4$ ones. Considering overall data published in Literature on SLNB, inguinal MTS are found in $26.2 \%$ of all patients (45 out of 172 ): $22.2 \%$ of $\mathrm{T} 1 ; 17.3 \%$ of $\mathrm{T} 2 ; 38.5 \%$ of $\mathrm{T} 3$; and $28.6 \%$ of $\mathrm{T} 4$ patients.

Our series suggest that inguinal SLNB is indicated for all patients affected by anal cancer (obviously in the absence of large palpable inguinal lymph nodes, which must be directly biopsied) in order to select patients to submit to inguinal radiotherapy and avoid unnecessary treatment and associated morbidity. Also patients previously submitted to surgical manipulation in the anal or inguinal region could be submitted to SLNB, even if the migration of the tracer could be altered by previous anal surgery and the detection of inguinal nodes could be difficult. In case of absence of inguinal migration of the tracer, patient must be treated following the personal standard inguinal approach. In our series, five patients were previously submitted to surgery for an anal mass that revealed a squamous cancer with margins involved. Inguinal SLNB was performed without problems.

The second aim of the study was to value the incidence of FN lymph nodes after SLNB. De Jong et al (2010) suggested that inguinal SLNB has a limited value considering the incidence of FN after the procedure. Our series were compared with the published ones in order to value the global incidence of FN. The result of the review, including our experience, evidentiated that 6 out of 163 (3.7\%) lymph nodes negative at immunochemistry after SLNB developed inguinal MTS after a medium follow up of 27.3 months (range 5-50 months). FN lymph nodes developed in three T1N0 cancers, one T2N0 and one T3N0 (in the case of Mariani et al (2008), the stage was not specified). Data of the review are reported in Table 3.

Considering these data, a FN rate of $3.7 \%$ should be considered as acceptable for patients affected by anal cancer.

Moreover, 4 out of $5(80 \%)$ of FN were T1-T2 patients (in one case, $\mathrm{T}$ stage was not specified) confirming that SLNB is indicated in all T stage and not only in T1-T2 as suggested by Gretschel et al (2008), considering that long follow-up confirm that almost 2 out of 3 of T3-T4 patients are N0 or N1.

\section{CONCLUSIONS}

Up-to-date SLNB technique in the detection of inguinal MTS in patients affected by anal cancer should be considered as a standard of care. It is indicated for all $\mathrm{T}$ stages in order to select patients to be submitted to inguinal radiotherapy, avoiding morbidity associated to this treatment in patients negative for inguinal MTS.

\section{REFERENCES}

Bartelink H, Roelofsen F, Eschwege F, Rougier P, Bosset JF, Gonzalez DG, Peiffert D, van Glabbeke M, Pierart M (1997) Concomitant radiotherapy and chemotherapy is superior to radiotherapy alone in the treatment of locally advanced anal cancer: results of a phase III randomized trial of the European Organization for Research and Treatment of Cancer Radiotherapy and Gastrointestinal Cooperative Groups. J Clin Oncol 15(5): 2040-2049.

Bobin JY, Gérard JP, Chapet O, Romestaing P, Isaac S (2003) Lymphatic mapping inguinal and sentinel lymph node biopsy in anal cancers to avoid prophylactic inguinal irradiation. Cancer Radiother 7(Suppl.1): 85s-90s.

Castro LS, Mali Jr J, Neto JFR, Pedras DSV, Stoduto G, Pacheco JS, Valadao M, Correa JHS, Dias JA (2005) Inguinal sentinel node biopsy in epidermoid carcinoma of the anal canal: a pilot study. Applied Cancer Research 25(2): 71-74.

Damin DC, Rosito MA, Gus P, Spiro BL, Amaral BB, Meurer L, Cartel A, Schwartsmann G (2003) Sentinel lymph node procedure in patients with epidermoid carcinoma of the anal canal. Early experience. Dis Colon Rectum 46: 1032-1037.

Damin DC, Rosito MA, Schwartsmann G (2006) Sentinel lymph node in cacinoma of the anal canal: a review. EJSO 32: 247-252.

De Jong JS, Beukema JC, van Dam GM, Slart R, Lemstra C, Wiggers T (2010) Limited value of staging squamous cell carcinoma of the anal margin and canal using the sentinel lymph node procedure: a prospective study with long term follow-up. Ann Surg Oncol 17: 2656-2662.

De Nardi P, Carvello M, Canevari C, Passoni P, Staudacher C (2011) Sentinel node biopsy in squamous-cell carcinoma of the anal canal. Ann Surg Oncol 18(2): 365-370.

Francois E, Ortholan C, Darcourt J, Benezery K, Hebert C, Mari V, Follana P, Peyrottes Sr I, Gerard J (2010) Long follow-up after inguinal sentinel lymph node (SLN) detection for squamous cell carcinoma (SCC) of the anal canal and anal margin. 2010 Gastrointestinal Cancers Symposium (abstract 317).

Gerard J-P, Chapet O, Samiei F, Morignat E, Isaac S, Paulin C, Romestaing P, Favrel V, Mornex F, Bobin J-Y (2001) Management of inguinal lymph node metastases in patients with carcinoma of the anal canal. Experience in a series of 270 patients treated in Lyon and review of the Literature. Cancer 92: 77-84.

Gretschel S, Warnick P, Bembenek A, Dresel S, Koswig S, String A, Hünerbein M, Schlag PM (2008) Lymphatic mapping and sentinel lymph node biopsy in epidermoid carcinoma of the anal canal. Eur J Surg Oncol 34: 890-894.

Hirche C, Dresel S, Krempien R, Hunerbein M (2010) Sentinel node biopsy by indocyanine green retention fluorescence detection for inguinal lymph node staging of anal cancer: preliminary experience. Ann Surg Oncol 17: 2357-2362.

Keshtgar MRS, Amin A, Taylor I, Ell PJ (2001) The sentinel node in anal carcinoma. EJSO 27: 113-114.

Mariani P, Girodet J, De La Rochefordiere A, Benhamor M, Sastre X, Salmon R (2008) Sentinel lymph node (SLN) in anal carcinoma: preliminary results. Ann Oncol 19 (Suppl 6) vi 64: 140.

Mistrangelo M, Bellò M, Mobiglia A, Beltramo G, Cassoni P, Milanesi E, Cornaglia S, Pelosi E, Giunta F, Sandrucci S, Mussa A (2009a) Feasibility of the sentinel node biopsy in anal cancer. Q J Nucl Med Mol Imaging 53: 3-8.

Mistrangelo M, Mobiglia A, Mussa B, Bellò M, Pelosi E, Goss M, Bosso MC, Moro F, Sandrucci S (2002) The sentinel node in anal carcinoma. Tumori 88(3): S51-S52.

Mistrangelo M, Morino M (2009b) Sentinel lymph node biopsy in anal cancer: a review. Gastroenterol Clin Biol 33: 446-450.

Mistrangelo M, Pelosi E, Bellò M, Castellano I, Cassoni P, Ricardi U, Munoz FH, Racca P, Contu V, Beltramo G, Morino M, Mussa A (2010) Comparison of positron emission tomography scanning and sentinel node biopsy in the detection of inguinal node metastases in patients with anal cancer. Int J Radiat Oncol Biol Phys 77(1): 73-78.

Mistrangelo M, Pelosi E, Bellò M, Ricardi U, Milanesi E, Cassoni P, Baccega M, Filippini C, Racca P, Lesca A, Munoz FH, Fora G, Skanjeti A, Cravero F, Morino M (2012) Role of positron emission tomography-computed tomography in the management of anal cancer. Int J Radiat Oncol Biol Phys Sept 1 84(1): 66-72. 
Myerson RJ, Kong F, Birnbaum EH, Fleshman JW, Kodner IJ, Picus J, Ratkin GA, Read TE, Walz BE (2001) Radiation therapy for epidermoid carcinoma of the anal canal, clinical and treatment factors associate with outcome. Radiother Oncol 61: 15-22.

Nigro ND, Vaitkeicus VK, Basil C B (1974) Combined therapy for cancer of the anal canal: a preliminary report. Dis Colon Rectum 17(3): 354-356.

Papillon J, Montbarbon JF (1987) Epidermoid carcinoma of the anal canal: a series of 276 cases. Dis Colon Rectum 30: 324-333.

Peley G, Farkas E, Sinkovics I, Kovacs T, Keresztes S, Orosz Z, Koves I (2002) Inguinal sentinel lymph node biopsy for staging anal cancer. Scan J Surg 91: 336-338.

Perera D, Pathma-Nathan N, Rabbit P, Hewett P, Rieger N (2003) Sentinel node biopsy for squamous cell carcinoma of the anus and anal margin. Dis Colon Rectum 46: 1027-1031.

Rabbit P, Pathma-Nathan N, Collinson T, Hewett P, Rieger N (2002) Sentinel lymph node biopsy for squamous cell carcinoma of the anal canal. ANZ J Surg 72: 651-654.

Sapienza P, Mingoli A, Nicolanti V, Maldini G, Picchio M, Stipa F (1992) Massive metachronous inguinal metastases from cancer of anal margin. A clinical case report. Minerva Chir 47: 1207-1210.
Siegel R, Ward E, Brawley O, Jemal A (2011) Cancer statistics, 2011. The impact of eliminating socioeconomic and racial disparities on premature cancer deaths. CA Cancer J Clin 61: 212-236.

Spratt JS (2000) Cancer of the anus. J Surg Oncol 74: 173-174.

Ulmer C, Bembenek A, Gretschel S, Markwardt J, Koswig S, Slisow Schneider U, Schlag PM (2003) Sentinel node biopsy in anal cancer - a promising strategy to individualize therapy. Onkologie 26(5): 456-460.

Vajda K, Cserni G, Svebis M, Szekeres JP (2001) Our experience with the sentinel lymph node mapping in anal and colorectal cancer. Proktologia (Suppl 1): 39.

Wade DS, Herrera L, Castillo NB, Petrelli NJ (1989) Metastases to the lymph nodes in epidermoid carcinoma of the anal canal studied by a clearing technique. Surg Gynecol Obstet 169: 238-242.

This work is published under the standard license to publish agreement. After 12 months the work will become freely available and the license terms will switch to a Creative Commons AttributionNonCommercial-Share Alike 3.0 Unported License. 